\title{
Purificação parcial de inibidores de tripsina de sementes de Caesalpinia ferrea e Swartzia polyphylla e o efeito dos extratos protéicos sobre fungos fitopatogênicos
}

\author{
Adriana Bariani ${ }^{1 *}$; José Francisco de Carvalho Gonçalves ${ }^{1}$; Larissa Ramos Chevreuil ${ }^{1}$; José Renato Pereira \\ Cavallazzi²; Luiz Augusto Gomes de Souza ${ }^{3}$; Jania Lilia da Silva Bentes ${ }^{4}$; Silvana Cristina Pando ${ }^{5}$
}

\begin{abstract}
${ }^{1}$ Laboratório de Fisiologia e Bioquímica Vegetal, Instituto Nacional de Pesquisas da Amazônia, CEP: 69060-020, Manaus, Amazonas. ${ }^{2}$ Instituto de Ciências Biológicas, Universidade Federal do Amazonas, CEP: 69077-000, Manaus, Amazonas. ${ }^{3}$ Laboratório de Microbiologia, Instituto Nacional de Pesquisas da Amazônia, CEP: 69060-020, Manaus, Amazonas. ${ }^{4}$ Faculdade de Ciências Agrárias, Universidade Federal do Amazonas, CEP: 69077-000, Manaus, Amazonas. 5 Departamento de Bioquímica, Universidade Federal do Amazonas, CEP: 69077-000, Manaus, Amazonas. *Parte da Dissertação de Mestrado. PPG-CFT/INPA (2008).
\end{abstract}

Autor para correspondência: José Francisco de Carvalho Gonçalves (jfc@inpa.gov.br)

Data de chegada: 29/07/2011. Aceito para publicação em: 13/02/2012.

\section{RESUMO}

Bariani, A.; Gonçalves, J.F.C.; Chevreuil, L.R.; Cavallazzi, J.R.P.; Souza, L.A.G.; Bentes, J.L.S.; Pando, S.C.. Purificação parcial de inibidores de tripsina de sementes de Caesalpinia ferrea e Swartzia polyphylla e o efeito dos extratos protéicos sobre fungos fitopatogênicos Summa Phytopathologica, v.38, n.2, p.131-138, 2012.

Sementes de leguminosas apresentam alta concentração de inibidores de tripsina; estas proteínas estão envolvidas no metabolismo celular e também em mecanismos de defesa vegetal. A fim de confirmar ou não, a possível ação fungicida destas proteínas a partir de extratos de sementes de leguminosas arbóreas, o objetivo deste estudo foi detectar inibidores de tripsina em sementes de Caesalpinia ferrea (CfTI) e Swartzia polyphylla (SpTI) e testar os extratos contra os fungos fitopatogênicos Colletotrichum guaranicola, Corynespora cassiicola, Fusarium oxysporum e Sclerotium rolfsii, avaliando o crescimento micelial e a esporulação. Para tanto, amostras do material biológico vegetal, sementes finamente pulverizadas, foram submetidas à extração em $\mathrm{NaCl} 150 \mathrm{mM}$. Os extratos protéicos foram parcialmente purificados em coluna Sephadex G-100, submetidos à detecção dos inibidores e SDS-PAGE $(12,5 \%)$ e, utilizados nos bioensaios contra os fungos. O perfil eletroforético revelou uma única banda em CfTI e oito bandas em SpTI. Os extratos de C. ferrea e $S$. polyphylla exibiram efeito na diminuição da esporulação dos fungos testados, mas S. rolfsii foi inibido apenas por C. ferrea. Quanto ao crescimento micelial, os dois extratos tiveram efeito sobre $F$. oxysporum e $S$. rolfsii, ao passo que $C$. guaranicola foi inibido apenas por S. polyphylla, e C. cassiicola por C. ferrea. Concluiu-se que sementes de $C$. ferrea e $S$. polyphylla apresentam inibidores de tripsina. Além disso, os resultados sugerem que estas espécies de leguminosas arbóreas são promissoras no que concerne à prospecção de fungicidas naturais, uma vez que os extratos diminuíram o crescimento micelial e a esporulação de C. guaranicola, C. cassiicola, F. oxysporum e S. rolfsii.

Palavras-chave adicionais: Inbidores de proteinases, proteínas de defesa vegetal, espécies arbóreas tropicais.

\section{ABSTRACT}

Bariani, A.; Gonçalves, J.F.C.; Chevreuil, L.R.; Cavallazzi, J.R.P.; Souza, L.A.G.; Bentes, J.L.S.; Pando, S.C. Partial purification of trypsin inhibitors from Caesalpinia ferrea and Swartzia polyphylla seeds and effect of protein extracts on pathogenic fungi. Summa Phytopathologica, v.38, n.2, p.131-138, 2012.

Legume seeds present high concentration of trypsin inhibitors; these proteins are involved in both cell metabolism and plant defense mechanisms. In order to confirm or not a possible fungicidal action of these proteins from extracts of seeds of legume tree species, the aim this study was to detect trypsin inhibitors in seeds of Caesalpinia ferrea (CfTI) and Swartzia polyphylla (SpTI) and to test their extracts against the pathogenic fungi Colletotrichum guaranicola, Corynespora cassiicola, Fusarium oxysporum and Sclerotium rolfsii, evaluating mycelial growth and sporulation. Thus, samples of the plant material, finely powdered seeds, were extracted in $150 \mathrm{mM}$ $\mathrm{NaCl}$. The protein extracts were partially purified on Sephadex G100 column, subjected to detection of inhibitors and SDS-PAGE
(12.5\%), and used in bioassays against the fungi. The electrophoretic profile revealed a single band in CfTI and eight bands in SPTI. The extracts of C. ferrea and $S$. polyphylla had an effect in reducing sporulation of the tested fungi, but $S$. rolfsii was inhibited only by $C$. ferrea. As to mycelial growth, the two extracts showed an effect on $F$. oxysporum and $S$. rolfsii, while $C$. guaranicola was inhibited only by $S$. polyphylla, and C. cassiicola by $C$. ferrea. It was concluded that seeds of $C$. ferrea and $S$. polyphylla present trypsin inhibitors. In addition, the results suggest that these tropical tree species are promising for the exploration of natural fungicides, since the extracts reduced mycelial growth and sporulation of C. guaranicola, $C$. cassiicola, F. oxysporum and S. rolfsii.

Additional keywords: Proteinase inhibitors, plant defense proteins, tropical tree species. 
A diversidade de potenciais produtos da flora amazônica destacase no cenário nacional e internacional, pelo seu valor econômico comprovado para várias espécies, como a seringueira (Hevea brasiliensis), por fornecer o látex para a produção da borracha; o açaí (Euterpe oleracea), castanha-do-pará (Bertholletia excelsa), cupuaçu (Theobroma grandiflorum), copaíba (Copaifera multijuga), andiroba (Carapa guianensis), cedrorana (Cedrelinga catenaeformise), arabá (Swartzia polyphylla), pau-roxo (Peltogyne venosa) e jucá (Caesalpinia ferrea) pela produção de frutos, sementes e/ou resina, que são utilizados na indústria alimentícia, farmacêutica, agroquímica e de cosméticos; além das tradicionais espécies que apresentam valor madeirável (1). No entanto, pesquisas mais recentes relatam que esta diversidade de plantas, quando analiticamente investigada a partir de métodos fitoquímicos, bioquímicos e/ou biotecnológicos que privilegiem a prospecção de moléculas vegetais presentes em diferentes partes da planta, podem exibir potencial ainda mais elevado para aplicação industrial, uma vez que reservas estocadas (proteínas, lipídeos, carboidratos e metabólitos secundários) poderão ser utilizadas como princípios ativos na criação de novos produtos para a indústria $(2,3)$.

Dentre todos os constituintes orgânicos vegetais, especificamente as proteínas são encontradas em altos percentuais em sementes de leguminosas. Estas moléculas são fundamentais para o metabolismo celular (ação catalítica das enzimas), na sinalização de respostas às condições ambientais (fatores bióticos e abióticos), além de atuarem nos mecanismos de defesa das plantas, como por exemplo, os inibidores de proteinases (4).

A despeito do crescente interesse sobre os aspectos estruturais e funcionais dessa classe de proteínas, ainda há poucas informações sobre sua caracterização e potencialidades dos inibidores proteolíticos, em sementes de espécies da flora amazônica. O fato é que, esses inibidores são metabolicamente importantes em decorrência de algumas funções que exercem nas plantas, podendo atuar de maneira constitutiva ou induzida, no mecanismo de defesa contra o ataque de insetos e patógenos, como fonte de aminoácidos sulfurados, na regulação de proteinases endógenas, e como sinais de respostas às condições ambientais estressantes de caráter biótico ou abiótico $(5,6,7)$.

Considerando, por um lado, a importância dessas proteínas para o mecanismo de defesa das plantas, e por outro, que insetos, fungos e nematóides podem impor em torno de $40 \%$ de perda da produção agrícola mundial, vários estudos tem sido realizados envolvendo princípios ativos que atuem como agentes de defesa natural no manejo integrado de pragas, incluindo o isolamento de compostos naturais (inibidores de proteinases) e a produção de plantas transgênicas resistentes, minimizando as perdas e o uso indiscriminado de agrotóxicos $(8,9,10,11)$.

O objetivo deste estudo foi purificar inibidores de tripsina contidos nos tecidos de reserva de sementes de Caesalpinia ferrea $\mathrm{C}$. Mart e Swartzia polyphylla D. C., bem como testar o efeito antifúngico dos extratos protéicos provenientes destas sementes, visando confirmar ou não o potencial dos inibidores proteolíticos para obtenção de fungicidas naturais.

\section{MATERIAL E MÉTODOS}

Sementes de Caesalpinia ferrea e Swartzia polyphylla foram coletadas de uma árvore de cada espécie (matrizes selecionadas pelo critério de maior produção de sementes), cultivadas no arboreto de leguminosas, localizado no Campus III do Instituto Nacional de
Pesquisas da Amazônia (INPA), no município de Manaus/AM $\left(03^{\circ} 08^{\prime} \mathrm{S}\right.$ e $\left.60^{\circ} 01^{\prime} \mathrm{W}\right)$. Estas matrizes estão registradas no herbário do INPA com os seguintes números 228.022. (Caesalpinia ferrea) e 228.828 (Swartzia polyphylla).

Sementes inteiras foram trituradas até a obtenção de material finamente pulverizado, o qual foi homogeneizado em solução de $\mathrm{NaCl}$ $150 \mathrm{mM}$ na proporção $10 \%(\mathrm{p} / \mathrm{v})$. A suspensão foi mantida sob leve agitação durante $2 \mathrm{~h}$ a $25^{\circ} \mathrm{C}$; posteriormente foi centrifugada a $5000 \mathrm{x}$ $g$, durante 20 minutos, sob temperatura de $4{ }^{\circ} \mathrm{C}$. O sobrenadante foi submetido à diálise durante $48 \mathrm{~h}$ e liofilizado, resultando no extrato protéico.

A determinação da concentração de proteínas nos extratos protéicos e nas frações provenientes da cromatografia em Sephadex G-100 foi realizada a partir de leituras espectrofotométricas a $\lambda=660 \mathrm{~nm}$ (espectrofotômetro Spectrum UV-VIS SP-2000 UV), utilizando-se a BSA (Sigma) como padrão (12).

Os extratos protéicos $(200 \mathrm{mg})$ foram aplicados na coluna de filtração em gel, Sephadex G-100 $(62,5 \mathrm{~cm} \mathrm{x} \mathrm{1,5} \mathrm{cm).} \mathrm{A} \mathrm{resina} \mathrm{foi}$ previamente hidratada e equilibrada com tampão Tris- $\mathrm{HCl} 50 \mathrm{mM}$ pH 8,0 contendo $\mathrm{NaCl} 150 \mathrm{mM}$, com fluxo de $18 \mathrm{~mL} / \mathrm{h}$. As frações com atividade inibitória foram reunidas, dialisadas, liofilizadas e utilizadas nas etapas posteriores. O monitoramento do perfil cromatográfico foi realizado por espectrofotometria $\lambda=280 \mathrm{~nm}$ (espectrofotômetro Spectrum UV-VIS SP-2000 UV).

Para a detecção da atividade inibitória da tripsina, as amostras, em diferentes concentrações, foram incubadas com a tripsina $(50 \mu \mathrm{g}$ dissolvida em HCl $1 \mathrm{mM}$ - enzima comercial, Sigma) e o tampão Tris$\mathrm{HCl} 12,5 \mathrm{mM}$ pH 8,0, completando o volume de $2 \mathrm{~mL}$, durante 10 minutos a $37{ }^{\circ} \mathrm{C}$. Decorrido o tempo descrito, adicionou-se o substrato cromogênico, BAPNA 0,5 mM (benzoil-arginina-paranitroanilida, Sigma), prosseguindo-se a incubação durante 30 minutos a $37{ }^{\circ} \mathrm{C}$. A reação foi paralisada pela adição de ácido acético $30 \%$ (v/v) e a hidrólise do substrato pela enzima foi acompanhada espectrofotometricamente a $405 \mathrm{~nm}$ (espectrofotômetro Spectrum UV-VIS SP-2000 UV).

Para a eletroforese em gel de poliacrilamida contendo SDS foram preparados géis de concentração a 5\% e de separação a 12,5\% (13). As amostras $(30 \mu \mathrm{g})$ foram dissolvidas em tampão Tris- $\mathrm{HCl} 80 \mathrm{mM} \mathrm{pH}$ 6,8 contendo SDS $2 \%$, glicerol $10 \%$ e azul de bromofenol $(0,1 \%)$. A corrida foi realizada a $120 \mathrm{~V}, 15 \mathrm{~mA}$, durante 10 horas, em condições não redutoras. Como marcadores de massa molecular utilizou-se o BenckMark Protein Ladder, Invitrogen (10 a $220 \mathrm{KDa})$. Os géis foram corados com Coomassie Brilliant Blue (Sigma-Aldrich).

Os bioensaios foram realizados em placas de Petri esterilizadas, contendo meio de cultura BDA (200 g de batata, $20 \mathrm{~g}$ de dextrose, 20 $\mathrm{g}$ de ágar e água deionizada em quantidade suficiente para um volume de $1000 \mathrm{~mL}$ de solução). Para testar a atividade antifúngica, os diferentes extratos protéicos foram diluídos em água deionizada, esterilizados por filtragem em filtro Millipore $0,22 \mu \mathrm{m}$, acrescentados ao meio BDA fundente (aproximadamente $45^{\circ} \mathrm{C}$ ) e testados em diferentes concentrações de proteína total $(0,10,20,40$ e $80 \mu \mathrm{g} / \mathrm{mL})$. As proporções foram determinadas após a etapa de estimativa do teor de proteína de proteína total nos extratos. O controle foi constituído de meio BDA e água ultrapura. A partir de colônias, crescidas em meio BDA, em câmara de incubação B.O.D. a $25{ }^{\circ} \mathrm{C}$, foram obtidos discos de $5 \mathrm{~mm}$ de diâmetro. Estes discos foram transferidos para o centro de cada uma das placas componentes de cada tratamento e incubados em B.O.D. a $25^{\circ} \mathrm{C}$. O efeito dos extratos sobre o crescimento micelial foi analisado em intervalos de dois dias após a repicagem, determinando o crescimento radial das colônias em dois eixos ortogonais, com auxílio de régua milimetrada, sendo posteriormente calculada a média. Quando, 
em um dos tratamentos, o crescimento das colônias atingiu todo o diâmetro de uma das placas de Petri, o experimento foi interrompido.

A avaliação da produção de esporos foi realizada imediatamente após o término do ensaio, sendo avaliada no décimo dia após a repicagem para os fungos Corynespora cassiicola e Colletotrichum guaranicola, no trigésimo terceiro dia para o fungo Fusarium oxysporum e no sétimo dia para o fungo Sclerotium rolfsii. Os esporos de cada placa foram suspensos (20 mL de água ultrapura para as placas de $90 \mathrm{~mm}$ e $15 \mathrm{~mL}$ para as placas de $80 \mathrm{~mm}$ de diâmetro) e coletados com auxílio de pincel. Para cada placa, alíquota de $0,5 \mu \mathrm{L}$ foi transferida para uma lâmina de hemocitômetro (câmara de Neubauer), onde se procedeu a contagem de esporos com auxílio de microscópio óptico. Os dados das contagens foram transformados em esporos por $\mathrm{cm}^{2}$, considerandose a quantidade de estruturas reprodutivas produzidas na área tomada pela colônia em cada placa. Para o fungo $S$. rolfsii, foi quantificado o número de escleródios por placa de cada tratamento.

Os bioensaios com fungos foram arranjados experimentalmente no delineamento inteiramente casualisado (DIC), obedecendo o esquema fatorial $(4 \times 5)$ com 6 repetições. Os tratamentos foram desdobrados em quatro espécies de fungos por cinco concentrações de proteína total $(0,10,20,40$ e $80 \mu \mathrm{g} / \mathrm{mL})$. Com relação às duas espécies vegetais, os experimentos foram realizados separadamente (EXP I e EXP II), devido às questões relacionadas à quantidade de material biológico (sementes) para realizar concomitantemente os ensaios com os fungos. Para a análise estatística dos dados foram realizadas análises de variância simples (ANOVA) e as médias foram comparadas pelo teste de Tukey a $5 \%$ de probabilidade, sendo utilizados os programas estatísticos Systat 10.0 for Windows Autoplay e o Assistat 7.3 beta.

\section{RESULTADOS E DISCUSSÃO}

O teor de proteínas nas sementes das espécies estudadas foi maior para S. polyphylla (Tabela 1). Contudo, apesar de C. ferrea apresentar baixo conteúdo protéico, apresentou menor percentual da atividade residual da tripsina, indicando, potencialmente maior inibição enzimática.

A variação da atividade residual da tripsina pelos diferentes extratos pode ocorrer, uma vez que a especificidade dos inibidores por uma classe particular de proteases está associada à composição, à

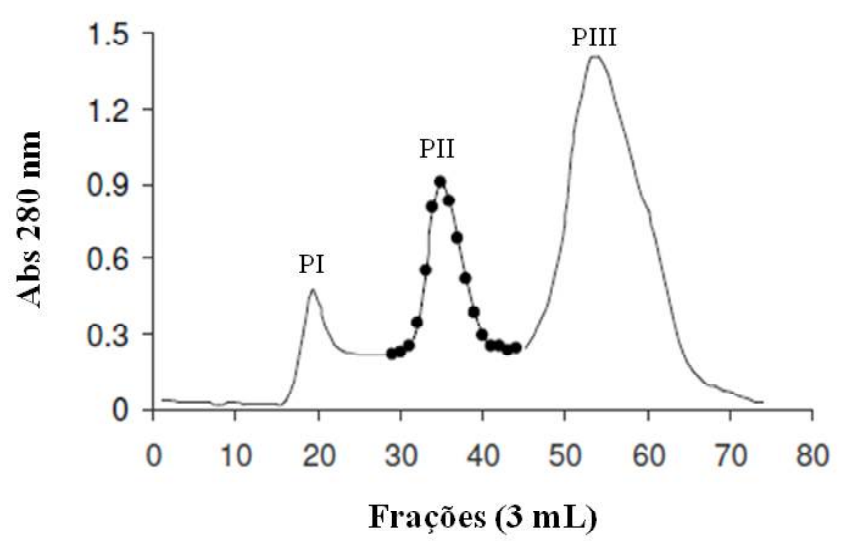

(A)
Tabela 1. Concentração de proteínas e atividade residual da enzima (ARE) tripsina bovina nos extratos protéicos provenientes de sementes de duas leguminosas arbóreas.

\begin{tabular}{lcc}
\hline & Proteína $\left(\boldsymbol{\mu g} \mathbf{~ m L}^{-1}\right)$ & ARE $(\mathbf{\%})$ \\
\hline Caesalpinia ferrea & 7,8 & 5 \\
Swartzia polyphylla & 40,3 & 66 \\
\hline
\end{tabular}

conformação do sítio reativo e à arquitetura global da molécula de inibidor, fatores estes, essenciais para a eficiência e estabilidade da proteína, visto que os resíduos de aminoácidos específicos presentes no sítio reativo, geralmente, correspondem aos resíduos do sítio ativo da enzima alvo, permitindo a formação de um complexo específico entre enzima e inibidor $(14,15)$.

Os extratos protéicos de $C$. ferrea e $S$. polyphylla foram submetidos à cromatografia de filtração em gel em Sephadex G-100, resultando em três picos distintos (PI, PII e PIII), onde o PII, para as duas espécies estudadas, representa as frações com atividade inibitória sobre a tripsina (Figura 1).

Após aplicação das amostras em Sephadex G-100, as frações com atividade inibitória sobre a tripsina foram designadas CfTI (inibidor de tripsina de $C$. ferrea) e SpTI (inibidor de tripsina de S. polyphylla), com rendimento de 23,5 e $0,6 \%$, respectivamente. Estes valores percentuais de rendimento podem ser considerados baixos. Na literatura especializada sobre inibidores proteolíticos, quase sempre têm sido apresentadas situações dessa natureza (16). Por exemplo, inibidores de tripsina isolados de sementes de Cassia obtusifolia e Albizzia kalkora, com destaque para a cromatografia de afinidade em tripsinaSepharose e de filtração em gel em Sephadex G-75 $(10,16)$.

No que diz respeito à curva de inibição da tripsina, pelos inibidores parcialmente purificados, observa-se que a ARE atingiu valores mínimos de 0,4 e $38 \%$ na presença de 1,9 de CfTI e $12 \mu \mathrm{g}$ de SpTI, respectivamente (Figura 2).

A atividade inibitória sobre a tripsina pelo CfTI, não diferiu significativamente entre as concentrações 1,9 e $12 \mu \mathrm{g}$ de inibidor, com inibição da atividade enzimática próxima a 100\%, ao passo que SpTI, entre as concentrações 4 e $10 \mu \mathrm{g}$, a inibição foi de $50 \%$, aumentando para $60 \%$ quando ensaiado com $12 \mu \mathrm{g}$.

A análise da curva de inibição permite avaliar a concentração

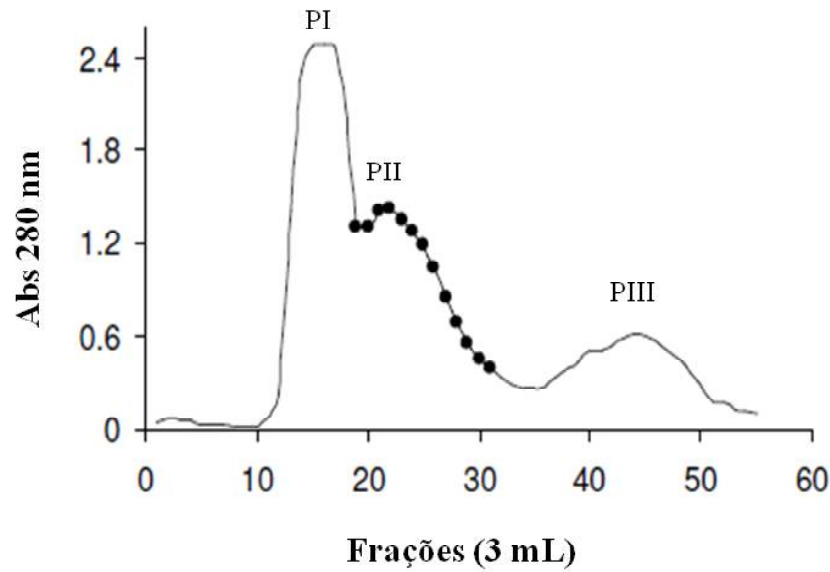

(B)

Figura 1. Cromatografia de filtração em gel em Sephadex G-100 (62,5 x 1,5 cm). (A) Caesalpinia ferrea. (B) Swartzia polyphylla. (•) Frações com atividade inibitória. Tampão de equilíbrio: Tris-HCl $50 \mathrm{mM} \mathrm{pH} \mathrm{8,0} \mathrm{contendo} \mathrm{NaCl} 150 \mathrm{mM}$. Amostras: $200 \mathrm{mg}$ do extrato protéico. Fluxo de eluição: 18 $\mathrm{mL} / \mathrm{h}$. 


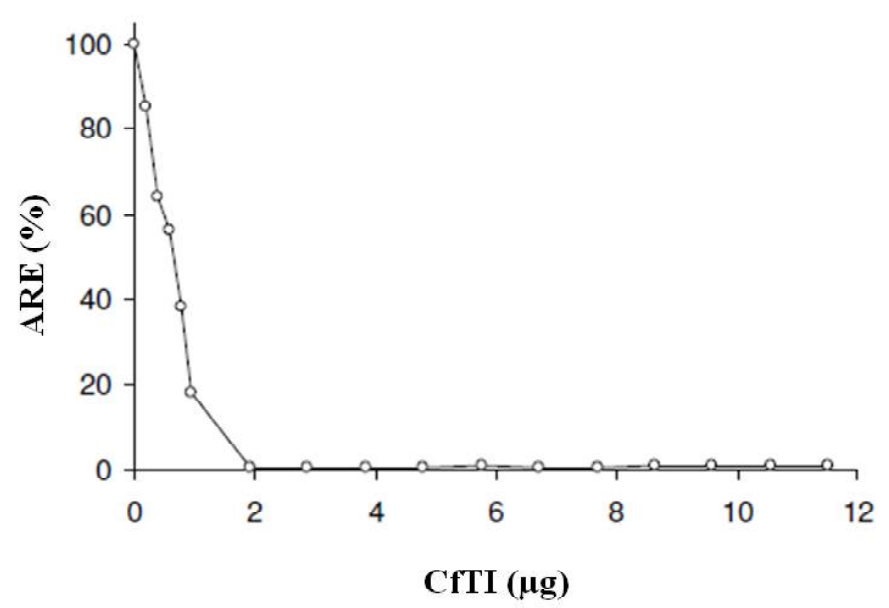

(A)

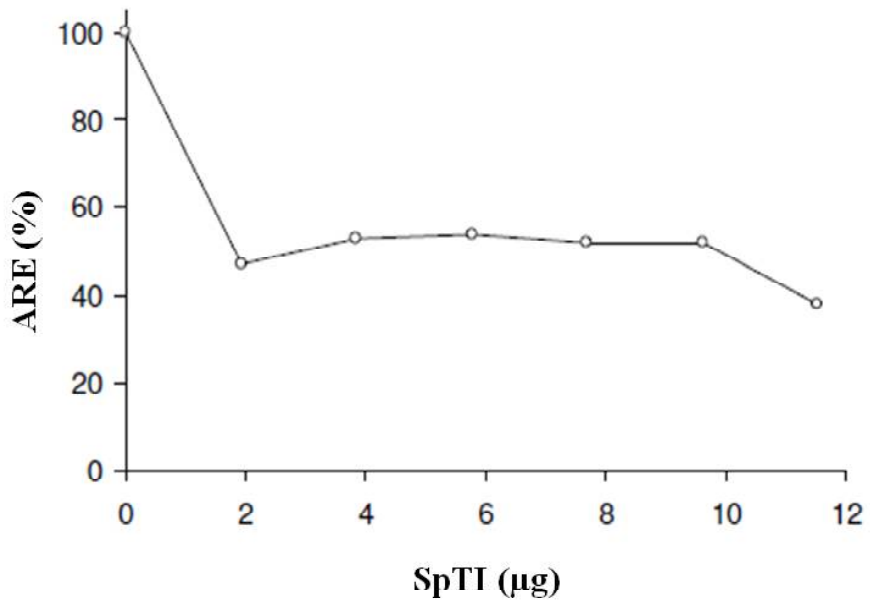

(B)

Figura 2. Curva de inibição da atividade da tripsina bovina pelas frações provenientes da cromatografia em Sephadex G-100. (A) Inibição por CfTI (Inibidor de tripsina de C. ferrea). (B) Inibição por SpTI (Inibidor de tripsina de S. polyphylla). A atividade residual da enzima (ARE) foi determinada a partir da incubação de diferentes concentrações dos inibidores com o BAPNA (Ná-Benzoyl-DL-arginine 4-nitroanilide hydrochloride).

necessária para promover a ligação enzima-inibidor. Adicionalmente, o complexo enzima-inibidor pode ser considerado semelhante ao complexo formado entre enzima-substrato. Nesse sentido, a especificidade de cada inibidor para a sua enzima alvo resulta no tipo de inibição exercida e da conformação e estrutura do sítio reativo $(9,17,18)$.

O perfil eletroforético dos extratos protéicos das sementes das espécies estudadas revelou distribuição de bandas de proteínas entre as faixas de massa moleculares de aproximadamente 10 e 80 KDa (Figura 3).

No que se refere ao perfil eletroforético dos inibidores de tripsina parcialmente purificados, verifica-se que CfTI apresentou uma banda protéica principal, com massa molecular em torno de $10 \mathrm{KDa}$, ao passo que em SpTI a distribuição das bandas protéicas foi semelhante à encontrada no extrato protéico, indicando baixa eficiência da cromatografia em sephadex G-100 na separação das moléculas para esta espécie (Figura 3).

Tecnicamente, as bandas protéicas presentes na faixa entre 8 a 10 $\mathrm{KDa}$ e 18 a $22 \mathrm{KDa}$ sugerem a presença de inibidores de proteinases. Este fato foi observado para os extratos de C. ferrea e S. polyphylla. De maneira mais específica, os inibidores de serinoproteinases do tipo Kunitz e Bowman-Birk têm sido relatados na literatura científica apresentando massas moleculares variando de 3 a $25 \mathrm{KDa}$ $(19,20,21)$.

$\mathrm{O}$ efeito do extrato protéico de C. ferrea sobre o crescimento micelial do fungo $C$. guaranicolla não foi significativo, diferente dos resultados observados sobre a esporulação. Por outro lado, o extrato de $S$. polyphylla diferiu para o crescimento micelial e esporulação nas diferentes concentrações testadas (Figura 4).

O extrato protéico de C. ferrea atingiu a inibição máxima da esporulação verificada nesta pesquisa $(91 \%)$ no tratamento com 40 $\mu \mathrm{g} / \mathrm{mL}$, embora já fosse capaz de inibir em torno de $54 \%$ em concentrações protéicas menores $(20 \mu \mathrm{g} / \mathrm{mL})$. Quanto à S. polyphylla, em todas as concentrações testadas, houve diminuição no número de esporos, contudo, a inibição não foi superior a $45 \%$, mesmo na presença de $80 \mu \mathrm{g} / \mathrm{mL}$ de proteína.

Esses resultados indicam que, apesar dos extratos protéicos não interferirem no crescimento da colônia, os mesmos podem exercer efeito (e/ou dano) na reprodução do fungo, devido à diminuição significativa na produção de esporos. Desta forma, a utilização desses extratos para o controle de C. guaranicola não impede que o fungo inicie o processo de infecção das plantas, mas pode atuar na redução do inóculo no campo, resultando na diminuição da disseminação da doença.

Pesquisas envolvendo extratos vegetais sobre o crescimento de Colletotrichum gloeosporioides demonstram propriedades antifúngicas,

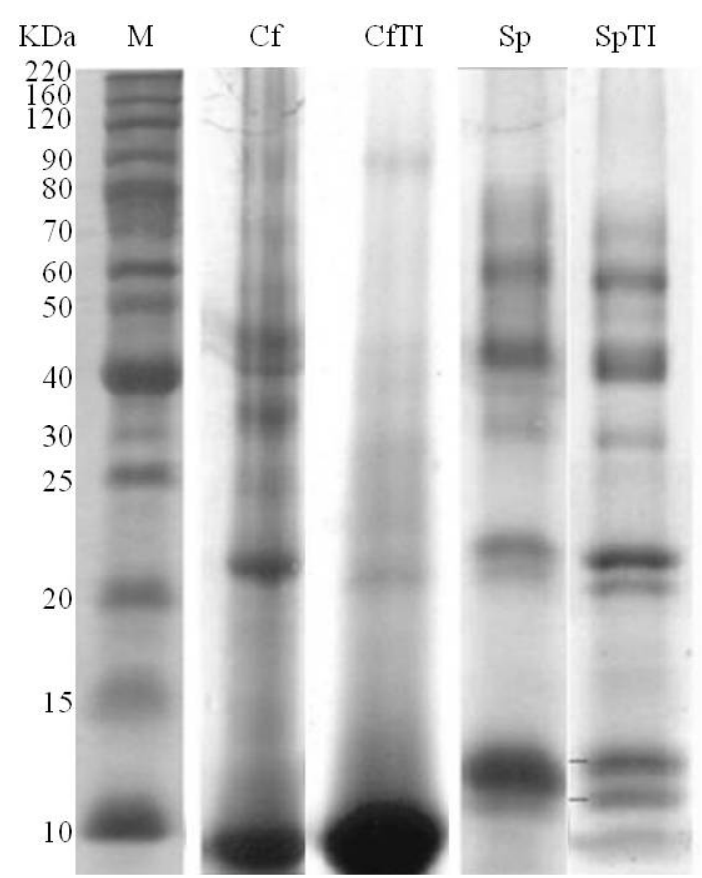

Figura 3. Eletroforese em SDS-PAGE (12,5\%). (KDa): Quilodalton. (M): Marcador de massa molecular. (Cf): Extrato protéico de Caesalpinia ferrea. (CfTI): Inibidor de tripsina de Caesalpinia ferrea. (Sp): Extrato protéico de Swartzia polyphylla. (SpTI): Inibidor de tripsina de Swartzia polyphylla. Amostras: $30 \mu \mathrm{g}$. Corrida em condições não redutoras. 


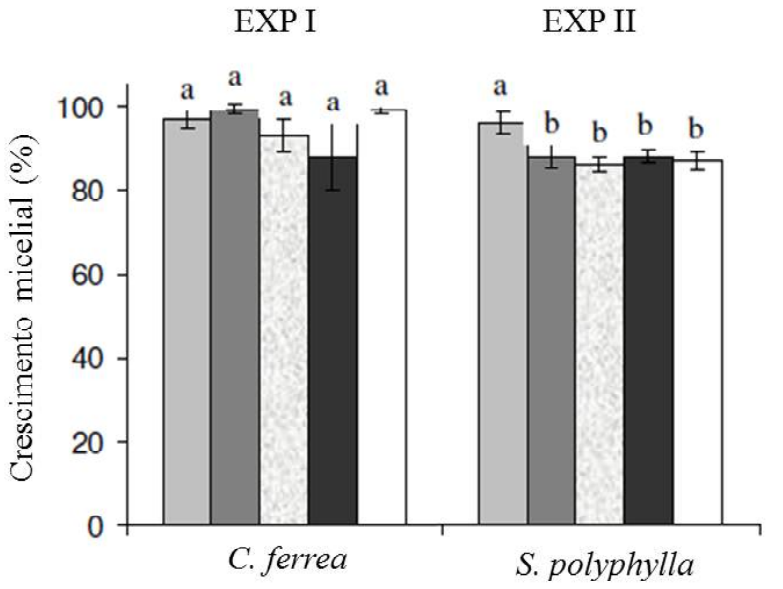

Concentração de proteína $(\mu \mathrm{g} / \mathrm{mL})$
EXP I

EXP II

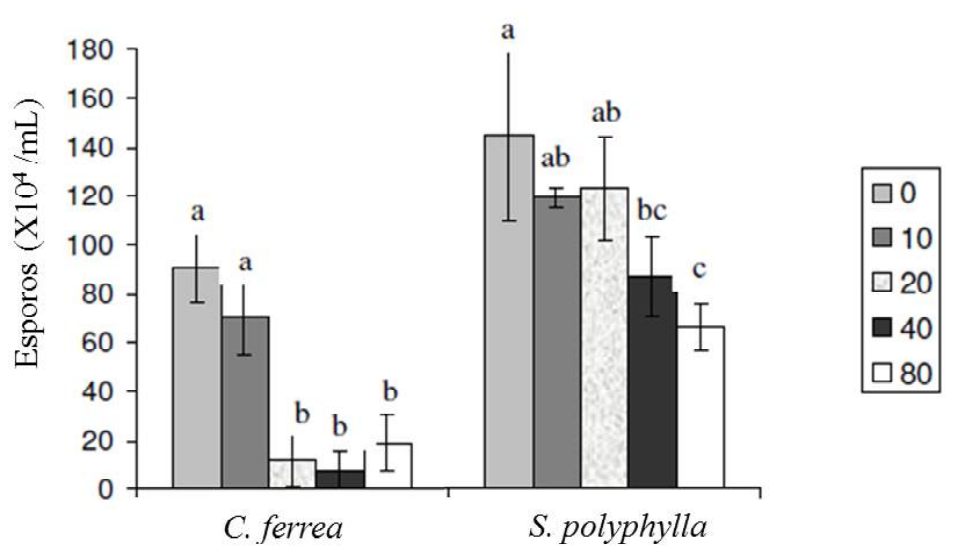

Concentração de proteína $(\mu \mathrm{g} / \mathrm{mI})$

(A)

(B)

Figura 4. Efeito dos extratos protéicos (concentrações de 0,10,20,30,40 e $80 \mu \mathrm{g} / \mathrm{mL}$ ) sobre o crescimento micelial (A) e esporulação de colônias (B) de Colletotrichum guaranicola. (0) Controle representado pelo crescimento fúngico em meio batata-dextrose-ágar sólido. As barras representam os desvios padrão. Médias seguidas da mesma letra não diferem estatisticamente pelo teste de Tukey a $5 \%(\mathrm{n}=30)$.

com diminuição do crescimento micelial e da esporulação (22). Adicionalmente, extratos de Eucalyptus citriodora inibiram $70 \%$ da germinação de esporos de Colletotrichum lagenaria (23).

Estudos demonstram que inibidores de proteinases apresentam efeito sobre fungos fitopatogênicos, podendo inibir o crescimento micelial, a esporulação, a morfologia e/ou germinação de esporos, a exemplo dos inibidores de tripsina isolados de sementes de Cassia obtusifolia testados contra o fungo Pieris rapae, das espécies Crotalaria juncea, Crotalaria spectables, Bauhinia variegata var. candida e Phaseolus vulgaris, que inibiram o crescimento micelial de Colletotrichum graminicola do sorgo $(10,16,24)$.

O crescimento micelial de $C$. cassiicola divergiu entre as concentrações de proteínas e as espécies estudadas nas concentrações acima de $20 \mu \mathrm{g} / \mathrm{mL}$ do extrato protéico de $C$. ferrea houve inibição, enquanto $S$. polyphylla não apresentou efeito significativo (Figura 5).

Quanto à esporulação de C. cassiicola, a inibição máxima ocasionada pelos extratos de C. ferrea e S. polyphylla foi de 74 e $47 \%$, respectivamente (Figura 5).

Estes resultados evidenciam a especificidade de cada extrato, considerando que a curva de crescimento do fungo é um parâmetro que fornece valores indicativos a respeito do efeito do extrato, em diferentes concentrações, sobre o desenvolvimento micelial de cada espécie fúngica, como por exemplo, no trabalho com extratos de Caesalpinia bonducella, que inibiram o crescimento micelial de Fusarium chlamydosporum, Rhizoctonia bataticola, Aspergillus niger e Alternaria alternata (25).

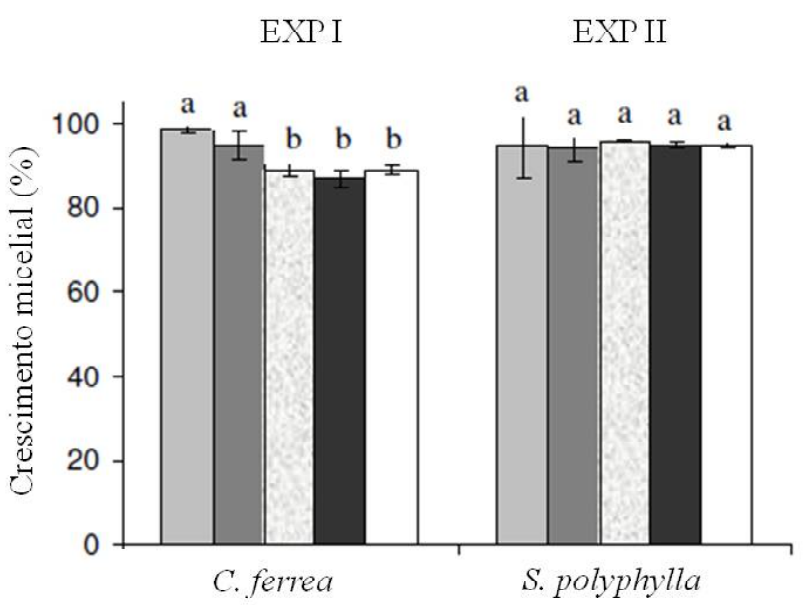

Concentração de proteína $(\mu \mathrm{g} / \mathrm{mL})$

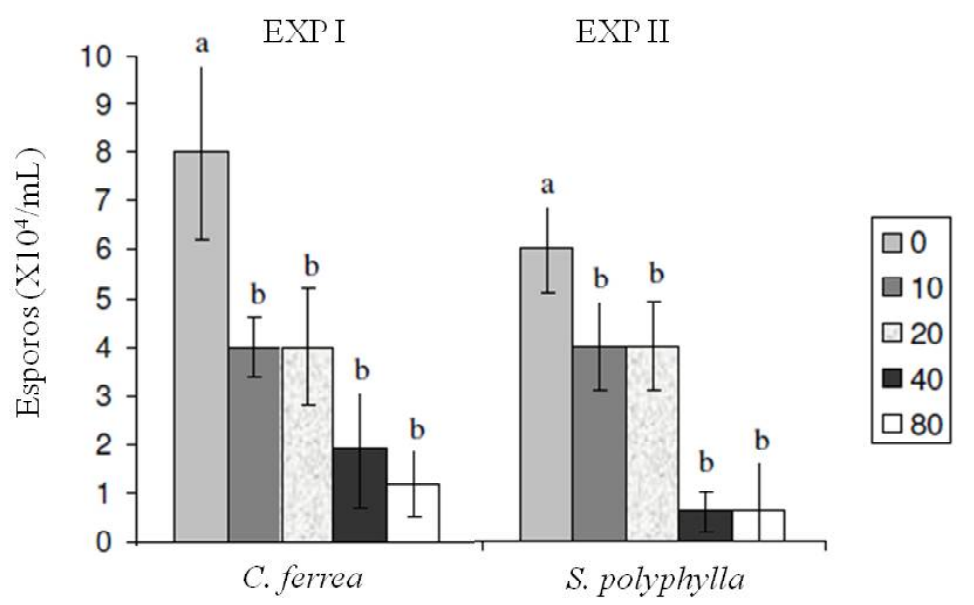

Concentração de proteína $(\mu \mathrm{g} / \mathrm{mL})$

(A)

(B)

Figura 5. Efeito dos extratos protéicos (concentrações de 0,10,20,30, 40 e $80 \mu \mathrm{g} / \mathrm{mL}$ ) sobre o crescimento micelial (A) e esporulação de colônias (B) de C. cassiicola. (0) Controle representado pelo crescimento fúngico em meio batata-dextrose-ágar sólido. As barras representam os desvios padrão. Médias seguidas da mesma letra não diferem estatisticamente pelo teste de Tukey a $5 \%(n=30)$. 
A análise de variância a respeito dos extratos protéicos sobre o crescimento micelial e a esporulação de colônias de $F$. oxysporum apresentou diferença estatística entre os tratamentos, indicando efeito sobre este fungo, afetando a estrutura vegetativa e reprodutiva (Figura 6).

$\mathrm{O}$ efeito dos extratos protéicos de C. ferrea sobre o crescimento micelial do fungo, quando comparadas com o controle, demonstrou que apenas a concentração de $80 \mu \mathrm{g} / \mathrm{mL}$ apresentou diferença entre as concentrações testadas. Diferentemente, a diminuição do número de conídios ocorreu na presença de 40 e $80 \mu \mathrm{g} / \mathrm{mL}$ do extrato protéico, com inibição em torno de 57 e $73 \%$, respectivamente.
No que diz respeito ao extrato protéico de $S$. polyphylla, o crescimento da colônia e o número de conídios foi reduzido apenas $10 \%$ e $47 \%$, respectivamente, na concentração de $80 \mu \mathrm{g} / \mathrm{mL}$.

Estudos envolvendo inibidores de tripsina do milho demonstram a inibição do crescimento micelial e esporulação de Fusarium oxysporum com 7,1 mM do inibidor (26). Ao passo que o inibidor isolado de feijão lima inibiu o crescimento do mesmo fungo com 1,9 $\mathrm{mM}$ (27). Uma glicoproteína (EcV) isolada de Enterolobium contortisiliqum inibiu o crescimento e a germinação de esporos de Fusarium solani nas concentrações de 10 e $20 \mu \mathrm{g} / \mathrm{mL}$ (28).

Quanto ao crescimento micelial de $S$. rolfsii, as concentrações

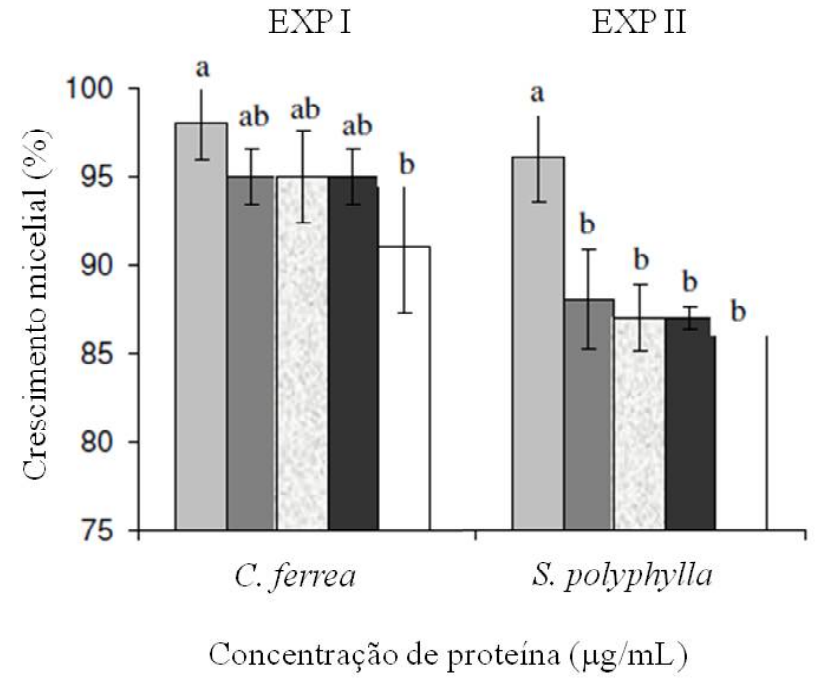

(A)

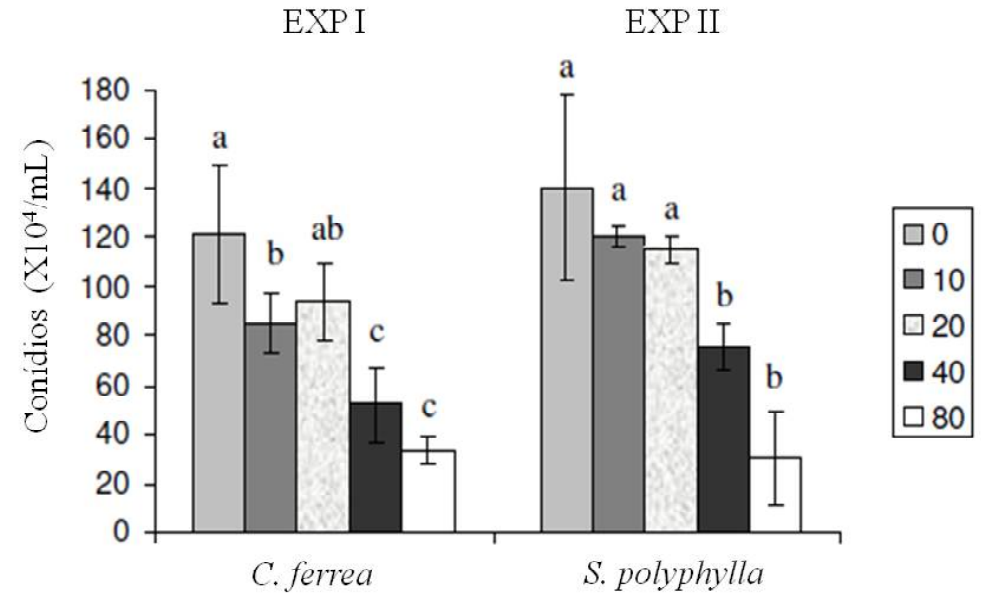

Concentração de proteína $(\mu \mathrm{g} / \mathrm{mL})$

(B)

Figura 6. Efeito dos extratos protéicos (concentrações de 0,10,20,30,40 e $80 \mu \mathrm{g} / \mathrm{mL}$ ) sobre o crescimento micelial (A) e esporulação de colônias (B) de F. oxysporum. (0) Controle representado pelo crescimento fúngico em meio batata-dextrose-ágar sólido. As barras representam os desvios padrão. Médias seguidas da mesma letra não diferem estatisticamente pelo teste de Tukey a $5 \%(n=30)$.

\section{EXP I}

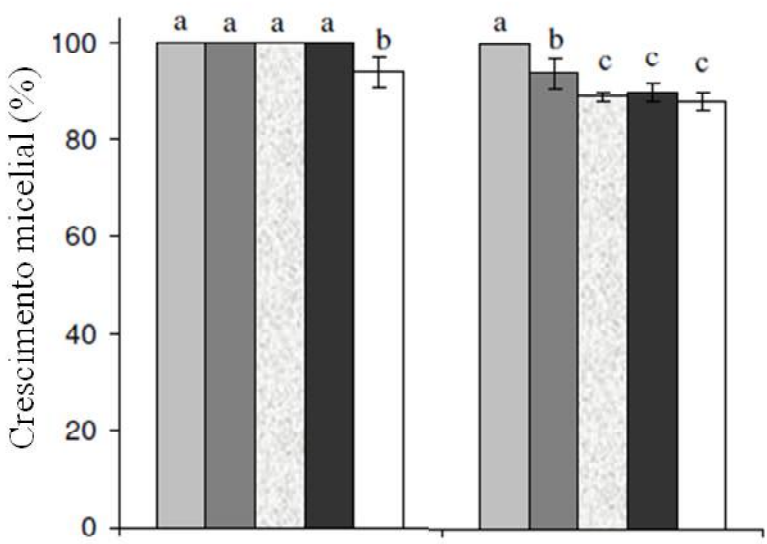

C. ferrea
EXP II

S. polyphylla

Concentração de proteína $(\mu \mathrm{g} / \mathrm{mL})$

EXP I

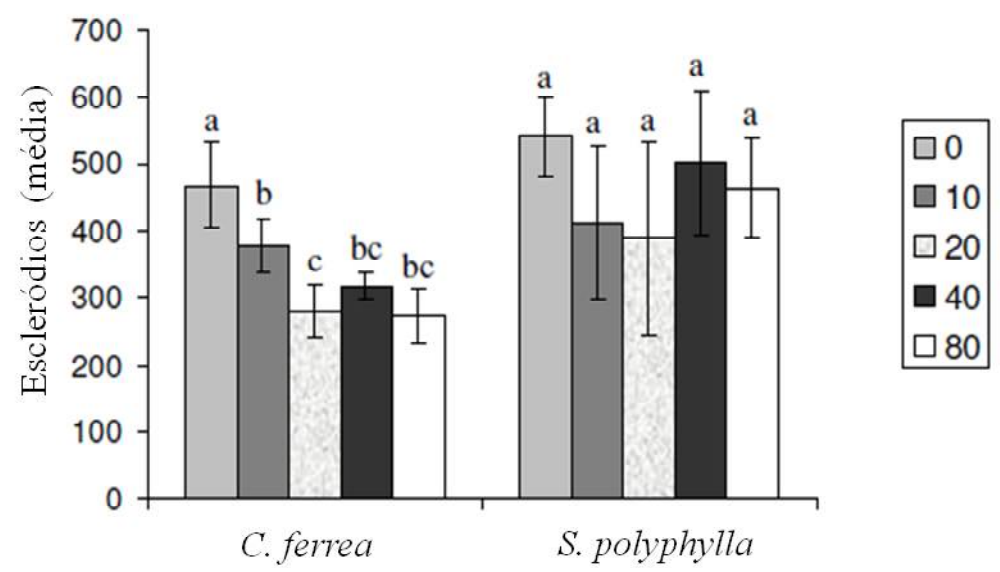

Concentração de proteína $(\mu \mathrm{g} / \mathrm{mL})$

(A)

(B)

Figura 7. Efeito dos extratos protéicos (concentrações de 0,10,20,30, 40 e $80 \mu \mathrm{g} / \mathrm{mL}$ ) sobre o crescimento micelial (A) e produção de escleródios (B) de $S$. rolfsii. (0) Controle representado pelo crescimento fúngico em meio batata-dextrose-ágar sólido. As barras representam os desvios padrão. Médias seguidas da mesma letra não diferem estatisticamente pelo teste de Tukey a $5 \%(n=30)$. 
protéicas testadas diferiram estatisticamente entre si ao nível de 5\% de probabilidade, ao passo que na produção de escleródios, não houve efeito significativo para as diferentes concentrações do extrato de $S$. polyphylla (Figura 7).

Os resultados sugerem que cada extrato apresenta características distintas diretamente associadas à sua especificidade, que podem estar relacionadas às características próprias de cada gênero e/ou espécie tanto da planta quanto do patógeno. Fato corroborado no estudo com diferentes concentrações de extratos de ritidoma, casca, caule, fruto e sementes de espécies de Swartzia ( $S$. argentea, S. laevicarpa, $S$, panacoco, $S$. polyphylla e $S$. sericea), em que se verificou diferenças significativas entre as médias do crescimento micelial de fungos degradadores de madeira (Pycnoporus sanguineus, Trametes villosa $\mathrm{e}$ Lenzites trabea) (29). Outros estudos envolvendo extratos vegetais de onze espécies apresentaram efeito antifúngico contra sete fungos fitopatogênicos (Botrytis cinerea, Fusarium oxysporum, Sclerotium rolfsii, Rhizoctonia solani, Verticillium dahliae, Botryosphaeria dothidea e Pythium ultimum), reduzindo o crescimento micelial em aproximadamente $40 \%$ (30).

Extratos vegetais podem atuar na redução de doenças e pragas ocasionadas nas plantas, a exemplo do LONLIFE, produto natural à base de extratos cítricos. Diante dos indícios científicos já descritos na literatura sobre a ação eficaz de compostos naturais contra agentes fitopatogênicos e, a partir dos resultados obtidos nesta pesquisa, conclui-se que $C$. ferrea e $S$. polyphylla são espécies promissoras para a produção de produtos naturais para controle de fungos, uma vez que seus extratos protéicos diminuíram o crescimento micelial e a esporulação de C. guaranicola, C. cassiicola, F. oxysporum e S. rolfsii.

\section{AGRADECIMENTOS}

Os autores agradecem a equipe do Laboratório de Fisiologia e Bioquímica Vegetal (INPA-LFBV) pelo suporte na condução dos experimentos. Também somos gratos ao CNPq pelas concessões das bolsas de mestrado, de pesquisa (PCI) e de produtividade (PQ) e a CAPES pelo financiamento desta pesquisa por meio do Programa de Colaboração Acadêmica (CAPES/PROCAD - 2006), além do projeto Bionorte - CNPq (número 554307/2010-3) pelo apoio a publicação.

\section{REFERÊNCIAS BIBLIOGRÁFICAS}

1. Clay, J.W.; Sampaio, P.T.B.; Clement, C.R. Biodiversidade amazônica: 79 exemplos e estratégias de utilização. Manaus: Instituto Nacional de Pesquisas da Amazônia/Programa de Desenvolvimento Empresarial e Tecnológico. 2000. 409 p.

2. Gonçalves, J.F.C.; Fernandes, A.V.; Oliveira, A.F.M.; Rodrigues, L.F.; Marenco, R.A. Primary metabolism components of seeds from Brazilia Amazon tree species. Brazilian Journal of Plant Physiology, Londrina, v. 14, p. 139 - 142, 2002.

3. Marques, D.D.; Sartori R.A.; Lemos, T.L.G.; Machado, L.L.; Souza, J.S.N. Monte, F.J.Q. Chemical composition of the essential oils from two subspecies of Protium heptaphyllum. Acta Amazonica, Manaus, v. 40, n. 1, p. $227-230,2010$.

4. Richardson, M. Seed storage proteins: the enzyme inhibitors. In: L.J. Rogers. Methods in plant biochemistry. London: Academic Press, 1991. v. 5, p. $259-305$.

5. Ragg, E.M.; Galbusera, V.; Scarafoni, A.; Negri, A.; Tedeschi, G.; Consonni, A.; Sessa, F.; Duranti, M. Inhibitory properties and solution structure of a potent Bowman - Birk protease inhibitor from lentil (Lens culinaris, L) seeds. FEBS Journal, Malden, v. 273, p. $4024-4039,2006$.
6. Marra, B.M.; Souza, D.S.L.; Aguiar, J.N.; Firmino, A.A.P.; Sarto, R.P.D.; Silva, F.B.; Almeida, C.D.S.; Cares, J.E.; Continho, M.V.; Martins-De-Sá, C.; Franco, O.L.; Grossi-De-Sá, M.F. Protective effects of a cysteine proteinase propeptide expressed in transgenic soybean roots. Peptides, New York, v. 30, p. 825 - 831, 2009.

7. Calderon, L.A.; Almeida Filho, H.A.; Teles, R.C.L.; Medrano, F.J.; Bolch Jr., C.; Santoro, M.M.; Freitas, S.M. Purification and structural stability of a trypsin inhibitor from Amazon Inga cylindrica [Vell.] Mart. seeds. Brazilian Journal of Plant Physiology, Londrina, v. 22, p. $73-79,2010$.

8. Herrera-Estrella, L. Transgenic plants for tropical regions: some considerations about their development and their transfer to the small farmer. Proceedings of the National Academy of Sciences of the USA, Washington, v. 96, p. 5978 - 5981, 1999.

9. Haq, S.K.; Atif, S.M.; Khan, R.H. Protein proteinase inhibitor genes in combat against insects, pests, and pathogens: natural and engineered phytoprotection. Archives of Biochemistry and Biophysics, New York, v. 431, p.145 - 159, 2004.

10. Liao, H.; Ren, W.; Kang, Z.; Jiang, J-H.; Zhao, X-J.; Du, F. A trypsin inhibitor from Cassia obtusifolia seeds: isolation, characterization and activity against Pieris rapae. Biotechnology Letters, Dordrecht, v. 29, p. $653-658,2007$.

11. Macedo, M.L.; Freire, M.G.M.; Franco, O.L.; Migliolo, L.; Oliveira, C.F.R. Practical and theoretical characterization of Inga laurina Kunitz inhibitor on the control of Homalinotus coriaceus, Comparative Biochemistry and Physiologya, Part B, New York, v. 158, p. $164-172,2011$.

12. Lowry, O.H.; Rosebrough, N.J.; Farr, A.L.; Randall, R.J. Protein measurement with the folin phenol reagent. Journal of Biological Chemistry, Bethesda, v. 193, p. 265 - 275, 1951.

13. Laemmli, U. K. Clevage of structural proteins during the assembly of the head of bacteriophage T4. Nature, London, v. 227, p. $680-685,1970$.

14. Bode, W.; Huber, R. Structural basis of the endoproteinase-protein inhibitor interaction. Biochimica et Biophysica Acta, Amsterdam, v. 1477, p. $241-252,2000$.

15. Krauchenco, S.; Pando, S.C.; Marangoni, S.; Polikarpov, I. Crystal structure of the Kunitz (STI)-type inhibitor from Delonix regia seeds. Biochemical and Biophysical Research Communications, San Diego, v. 312, p. 1303 - 1308, 2003.

16. Zhou, J.Y.; Liao, H.; Zhang N.H.; Tang, L.; Xu, Y.; Chen, F. Identification of a Kunitz inhibitor from Albizzia kalkora and its inhibitory effect against pest midgut proteases. Biotecnology Letters, Dordrecht, v. 30, p. 1495 - 1499, 2008.

17. Vieira, E.C. Bioquímica celular e biologia molecular, 2. ed. São Paulo: Atheneu, 1999. 360p.

18. Legowska, A.; Debowski, D.; Lesner, A.; Wysocka, M.; Rolka, K. Introduction of non-natural amino acid residues into the substrate - specific P position of trypsin inhibitor SFTI-1 yields potent chymotrypsina and cathepsin G inhibitors. Bioorganic \& Medicinal Chemistry, Kidlington, v. 17, p. 3302 - 3307, 2009.

19. Carlini, C. R.; Grossi-De-Sá, M. F. Plant toxic proteins with insecticidal properties. A review on their potentialities as bioinsecticides. Toxicon, Kidlington, v. 40, p. 1515 - 1539, 2002.

20. Park, E.Y.; Kim, J-A.; Kim, H-W.; Kim, Y.S.; Song, H.K. Crystal structure of the Bowman-Birk inhibitor from barley seeds in ternary complex with porcine trypsin. Journal of Molecular Biology, London, v. 343, p. $173-186,2004$

21. Ruan, J.J.; Chen, H.; Shao, J.R.; Wu, Q.; Han, X.Y. An antifungal peptide from Fagopyrum tataricum seeds. Peptides, New York, 2011. (In press).

22. Ribeiro, L.F.; Bedendo, I.P. Efeito inibitório de extratos vegetais sobre Colletotrichum gloeosporioides - agente causal da podridão de frutos de mamoeiro. Scientia Agricola, Piracicaba, v. 56, p. $1267-1271,1999$.

23. Bonaldo, S.M.; Schwan-Estrada, K.R.F.; Stangarlin, J.R.; Tessmann, D.J.; Scapim, C.A. Fungitoxicidade, atividade elicitora de fitoalexinas e proteção de pepino contra Colletotrichum lagenaria pelo extrato aquoso de Eucalyptus citriodora. Fitopatologia Brasileira, Viçosa, v. 29, p. $128-134,2004$.

24. Pando, L.A. Caracterização físico-química e biológica de 
proteínas isoladas de sementes de leguminosas: lectinas e inibidores de proteinases. 2001. 107f. Tese (Doutorado em Biologia Funcional e Molecular) - Instituto de Biologia, Universidade Estadual de Campinas, Campinas.

25. Aqil, F.; Ahmad, I. Broad-spectrum antibacterial and antifungal properties of certain traditionally used Indian medicinal plants. World Journal of Microbiology \& Biotechnology, New York, v. 19 , p. $653-657,2003$.

26. Chen, Z.Y.; Brown, R.L.; Russin, J.S.; Lax, A.R.; Cleveland, T.E. A corn trypsin inhibitor with antifungal act inhibits Aspergillus flavus alpha-amylase. Phytopathology, ST Paul, v. 89, p. $902-$ $907,1999$.

27. Wong, J.H.; Ng, T.B. Lunatusin, a trypsin-stable antimicrobial peptide from lima beans (Phaseolus lunatus L.). Peptides, New York, v. 26, p. 2089 - 2092, 2005.

28. Moura, F.T.; Oliveira, A.S.; Macedo, L.L.; Vianna, A.L.B.R.; Andrade, L.B.S.; Martins-Miranda, A.S.; Oliveira, J.T.A.; Santos, E.A.;
Sales, M.P. de. Effects of a chitin-binding vicilin from Enterolobium contortisiliquum seeds on bean bruchid pests (Callosobruchus maculates and Zabrotes subfasciatus) and phytopathogenic fungi (Fusarium solani and Colletrichum lindemuntianum). Journal of Agricultural and Food Chemistry, Washington, v. 55, p. $260-266,2007$.

29. Jesus, M.A. Efeito dos extratos obtidos de Swartzia argentea Spruce ex Benth., S. laevicarpa Amshoff, $S$. panococo (Aublet) Cowan, S. polyphylla DC. E de S. sericea Vogel da Amazônia Central sobre fungos degradadores de madeira. 2003. 99f. Tese (Dourado em Ciências Biológicas) - Instituto de Biociências, Universidade Estadual Paulista Júlio de Mesquita Filho, Rio Claro.

30. Exsteen, B.D.; Pretorius, J.C.; Nieuwoudt, T.D.; Zietsman, P.C. Mycelial growth inhibition of plant pathogenic fungi by extracts of South African plant species. Annals of Applied Biology, Malden, v. 139, p. 243 - 249, 2001. 